Revista Iberoamericana, Vol. LXXI, Núm. 212, Julio-Septiembre 2005, 815-831

\title{
GLOBALIZACIÓN Y ÉTICA: LA TEOLOGÍA DE LA LIBERACIÓN EN LAS NOVELAS DE GRACIELA LIMÓN Y DEMETRIA MARTÍNEZ
}

\author{
POR \\ ELLEN MCCRAcKen \\ University of California, Santa Barbara
}

Uno de los cambios más profundos en la sociedad latinoamericana del siglo xx es la radicalización después del Segundo Concilio Vaticano (1961-1965) de varios grupos dentro de la Iglesia Católica, desde miembros de la alta jerarquía hasta elementos de los sectores populares.* El reconocimiento por parte de los concilios de Medellín, Colombia (1968) y de Puebla, México (1979) de que la Iglesia debe ejercer una opción preferencial para los pobres se basó en la idea del Gran Escándalo: después de 500 años de Cristiandad en el nuevo mundo, todavía existe inmensa pobreza y gran sufrimiento en toda Latinoamérica. La misión de la Iglesia debe ser servir a los pobres, ayudar a mejorar la vida aquí en este mundo en lugar de aconsejarlos a aguantar el sufrimiento ahora, para alcanzar la justicia divina en el juicio final. Por medio de grupos como las comunidades de base, la gente común, junto con algunos curas, comenzó a educarse tras una relectura colectiva de la Biblia, enfocada en las problemáticas sociales tanto históricas como inmediatas. Este proceso los condujo a las raíces estructurales de su pobreza, el sistema económico que mantiene gran desigualdad entre los ricos y los pobres. De ahí, paulatinamente, varias comunidades iniciaron su militancia contra la injusticia económica, juntándose con otros grupos políticos que lucharon por el cambio radical de la sociedad.

Efectivamente, estos movimientos religiosos y sociales de la segunda mitad del siglo xx acabaron por afectar la producción cultural de Latinoamérica. Las ideas y la práctica de la teología de la liberación se registra en la obra de escritores como Manlio Argueta, Vicente Leñero, Marcos Aguinis y Julio Cortázar. ${ }^{1}$ También podemos señalar varios textos sociales bien conocidos que materializan aspectos de la liberación teológica como las manifestaciones semanales de las Madres de la Plaza de Mayo en Buenos Aires, la comunidad de Solentiname en Nicaragua fundada por Ernesto Cardenal y los valientes discursos, sermones y cartas de Oscar Arnulfo Romero, arzobispo de San Salvador. Por medio de las palabras, del diálogo y de la presencia comunal en los espacios públicos, estos textos insisten en la denuncia de la injusticia, la acción comunitaria para liberarse de la

\footnotetext{
* Quisiera agradecer a Sara Poot-Herrera, a Alberto Sandoval-Sánchez y a Frances Aparicio por sus cuidadosas y pacientes lecturas de este ensayo.

${ }^{1}$ Véase Manlio Argueta, Un día en la vida;Vicente Leñero, Jesucristo Gómez; Marcos Aguinis, La cruz invertida; Julio Cortázar, "Apocalípsis en Solentiname”, en Nicaragua tan violentamente dulce.
} 
opresión y la reelaboración de los conceptos religiosos tradicionales. Esta reelaboración se suma a las palabras del recién fallecido obispo argentino Jorge Novak, “El verdadero cristiano debe reclamar la justicia” (13).

La teología de la liberación no se limitó a los problemas sociales específicamente latinoamericanos. Igual que la literatura y los otros textos sociales que elaboraban los ideales de la liberación política por medio de una nueva interpretación de la Biblia, la nueva teología cruzó las fronteras nacionales y fue adaptada a situaciones analógicas en otros lugares. Se desarrollaron también teorías semejantes en otras regiones del mundo como la teología de la liberación africana y las teologías alternativas de grupos oprimidos como las mujeres, los negros y los homosexuales. ${ }^{2}$ También esta teología contribuyó a una nueva conciencia global dentro de la Iglesia Católica norteamericana, cuando varios líderes y grupos populares apoyaron públicamente las luchas por la justicia en Latinoamérica y en los Estados Unidos, y enfatizaron los nexos comunes entre estos proyectos liberadores.

Del mismo modo se puede ver la influencia de la nueva teología en la novela posnacionalista de los chicanos en los Estados Unidos. Después del período de la consolidación del movimiento chicano de los años sesenta y setenta en el cual gran parte de la literatura resaltó el orgullo nacionalista de esta población minoritaria y la política de la identidad, varios autores comenzaron a integrar temas hemisféricos en su producción literaria. Las preocupaciones por la justicia social y por la ética se extendieron a la visión de un espacio fronterizo del suroeste, en el cual muchas veces la política hemisférica subyace a la construcción estética. Como han señalado Michael Hardt y Antonio Negri, lo local es un producto de la globalización. Las luchas locales de los latinos estadounidenses existen hoy en un espacio en el cual es cancelada la dialéctica del interior y el exterior. "It is false ... to claim that we can (re)establish local identities that are in some way outside and protected against the global flows of capital and Empire" [Es falso...reclamar que podemos reestablecer identidades locales que de alguna manera u otra estén fuera de los flujos globales del capital y del Imperio, y protegidas por ellos](45). Varios escritores chicanos posnacionalistas basan su construcción estética en una política hemisférica en la cual la justicia y la ética se construyen con respecto a la nueva multitud migratoria que trasciende las fronteras nacionales.

En la década de los ochenta muchos de los desplazados de las guerras civiles en Centroamérica buscaron refugio en el suroeste de los Estados Unidos. Al mismo tiempo, surgió en el país una inquietud creciente por el papel del gobierno estadounidense en exacerbar esta diáspora debido al sostén financiero y militar que aportó a los gobiernos represivos en esta región y su falta de apoyo a los refugiados que buscaron asilo. Esos sucesos históricos tuvieron gran impacto en algunos escritores latinos estadounidenses que expandieron sus preocupaciones literarias para abarcar lo latino dentro de un marco hemisférico. Dos novelistas chicanas que se identifican como católicas, feministas y ciudadanas hemisféricas, tras encontrarse involucradas directamente en la diáspora

2 Véase, por ejemplo, Elsa Tamez (ed.), Through Her Eyes: Women's Theology from Latin America; Ada María Isasi-Díaz y Yolanda Tarango, Hispanic Women's Prophetic Voice in the Church : Toward a Hispanic Women's Liberation Theology; Sharon D. Welch, Communities of Resistance and Solidarity: a Feminist Theology of Liberation; y Theo Witvliet, The Way of the Black Messiah: The Hermeneutical Challenge of Black Theology as a Theology of Liberation, trans. John Bowden. 
salvadoreña de los ochenta, ${ }^{3}$ llevaron al espacio literario esas experiencias y se enfocaron necesariamente en la teología de la liberación. Se ve la trasculturación hemisférica en sus novelas tanto en los temas políticos-religiosos como en el modelo discursivo que ofrece la teología de la liberación, estructura reinventada en la creación estética de estas novelistas chicanas.

Graciela Limón, radicada en Los Angeles y profesora de literatura en la Universidad Jesuita Loyola Marymount, participó en las manifestaciones semanales de 1986 a 1991 en La Placita en el centro de Los Angeles y frente al Edificio Federal para protestar contra el apoyo del gobierno norteamericano al gobierno militar salvadoreño. A las seis de la mañana los miércoles, junto con figuras muy conocidas como el actor Martin Sheen, los manifestantes llevaban una cruz grande en procesión y a veces yacían en la acera para dibujar trazos de cuerpos que representaban a los muertos en la guerra salvadoreña. Limón también trabajó con salvadoreños refugiados -en la iglesia Nuestra Señora de los Angeles, en La Placita- que pedían asilo en los Estados Unidos a la vez que el pastor Padre Luis Olivares declaró la iglesia un santuario. ${ }^{4}$ En 1990 Limón viajó a El Salvador con otros representantes de su universidad para conmemorar el primer aniversario del asesinato de los jesuitas de la Universidad Centroamericana. Estas experiencias la inspiraron a escribir la novela In Search of Bernabé (1993) en la cual reterritorializa la guerra civil salvadoreña en un espacio híbrido que cubre Centroamérica, México y California.

Demetria Martínez, poeta, periodista y novelista, que escribe desde Albuquerque, Nuevo México y Tucson, Arizona, también reterritorializa el conflicto salvadoreño al espacio fronterizo del suroeste. Nacida en 1960, si era muy joven en los turbulentos años sesenta durante la guerra de Vietnam, se radicaliza en los ochenta con las protestas contra la intervención estadounidense en otra guerra, la de El Salvador. Al terminar sus estudios universitarios en Princeton en 1982, regresó a Albuquerque, donde trabajó con un grupo de artistas católicas en Sagrada Arts Colony. Fue grandemente marcada después de asistir a una reunión organizada por los Quakers en Albuquerque, en la cual un refugiado guatemalteco contó su historia con la cara cubierta para proteger su identidad. En estos eventos de los refugiados daban testimonio de fe en la teología de la liberación, influyendo así sobre los norteamericanos que trabajaban en el Movimiento para dar santuario a los refugiados. ${ }^{5}$ Martínez comenzó a escribir poesía y periodismo sobre los conflictos centroamericanos y la ayuda financiera que proveyó a los militares en El Salvador el gobierno del Presidente Reagan. Aprendió de los testimonios que presentaron muchos refugiados que fueron perseguidos como católicos que luchaban en su país por la justicia

\footnotetext{
${ }^{3}$ Recientemente, la novelista Sandra Benítez ha añadido su voz a este diálogo narrativo de latinos estadounidenses sobre la guerra civil salvadoreña. Al comienzo de su novela The Weight of All Things, invoca los acontecimientos que narró también Limón en su novela: el asesinato de 35 personas que participaron en el funeral del Arzobispo Oscar Romero en marzo de 1980 y la masacre de seiscientos campesinos en mayo del mismo año en el río Sumpul.

${ }^{4}$ Como consecuencia de su acto de caridad, el Padre Olivares recibió una amenaza de muerte en 1987, firmada como “E.M” (Escuadrón de La Muerte), que él creyó se había enviado desde El Salvador. Véase Cockroft, 615-16.

${ }^{5}$ Martínez habló sobre estos hechos autobiográficos en una conferencia presentada en la Universidad de California, Santa Bárbara el 24 de mayo de 2001.
} 
social. En 1987, Martínez y un pastor protestante fueron acusados en un proceso federal por haber ayudado a dos refugiadas salvadoreñas a entrar ilegalmente a los Estados Unidos. Después de un largo juicio, fue declarada inocente. A partir de estas experiencias, Martínez recrea en su novela Mother Tongue (1994) la historia concreta de un exiliado salvadoreño y su relación con una participante en el Movimiento Santuario, en el suroeste estadounidense durante los años ochenta. Como Limón, basada en una relectura de la Biblia, Martínez extiende la crítica de las estructuras económicas desiguales en Latinoamérica a la desnaturalización de las estructuras patriarcales, e invita a sus lectores norteamericanos a participar en un nuevo significado de la globalización, en el cual ya no quedan reprimidos ciertos elementos de la inconsciencia política del imperio norteamericano.

Se puede proponer que tanto la literatura chicana como la teología de la liberación releen las grandes narrativas y los textos sociales desde la perspectiva de los oprimidos. Con un desarrollo dramático en las décadas de los sesenta y los setenta, después de incursiones iniciales en los años cincuenta, tanto el movimiento religioso como el literario respondieron a los problemas sociales de su momento histórico, promoviendo la justicia por medio de la palabra y la acción. Los escritores chicanos igual que los teólogos de la liberación inventaron narrativas con nuevos protagonistas en nuevas posiciones actanciales. ${ }^{6}$ Así como los pobres se hicieron sujetos activos con la apropiación de la nueva teología, los chicanos crearon una nueva identidad en su producción literaria y en su acción política. Desde esta perspectiva, Demetria Martínez nota que los escritores chicanos como Helena María Viramontes, Benjamín Sáenz y Luis Urrea y otros escritores latinos como Martín Espada, dan una voz a los desposeídos, desarrollando una especie de "literary liberation theology [teología literaria de la liberación]” (“What a moment...” 16).

Martínez y Limón inscriben su narrativa explícitamente en los discursos de la teología de la liberación latinoamericana. Trascendiendo los paralelos metafóricos, narrativos y sociales con una nueva práctica religiosa, éstas aportan una nueva perspectiva en sus novelas sobre las luchas contemporáneas por la justicia social en Latinoamérica. La teología de la liberación influye tanto en el contenido como en las estrategias narrativas de su escritura. Martínez y Limón resemantizan las narrativas bíblicas y resignifican las categorías tradicionales de lo bueno y lo malo, cuestionando así oposiciones binarias que eliminan todo proceso de negociación y cambio social. En estos términos, invitan a sus lectores norteamericanos a reconcebir la realidad a la luz de una frontera entre los Estados Unidos y Latinoamérica, que se desintegra al proponer una nueva conciencia social que trasciende, por ejemplo, las fronteras convenientes entre las naciones ricas y las pobres. Si la teología de la liberación aspira a la centralización de los pobres y los marginados en la conciencia moral de los sectores eclesiásticos y civiles de la sociedad latinoamericana, Limón y Martínez, de manera semejante, se proponen trasponer al nivel literario las guerras civiles de Centroamérica de los años ochenta con el propósito de crear conciencia social en los lectores estadounidenses. Crean un continuum hemisférico entre norte-sur y sur-norte en el cual los ciudadanos del norte se dan cuenta de su contribución a la

${ }^{6}$ Véase A. -J. Greimas, “Reflections on Actantial Models” en Susan Onega y José Angel García Landa, eds., Narratology: An Introduction. 
prolongación y agravamiento de los conflictos bélicos en el sur. Refuerzan una conciencia social hemisférica en la cual los norteños ayudan a los del sur, especialmente en los momentos de crisis ardua.

La globalización de Mother Tongue une el norte con el sur, lo personal con lo político, lo religioso con lo secular. Mary, una chicana de diecinueve años que protagoniza y narra la novela, ayuda a su madrina Soledad, quien es miembro activo del Movimiento Santuario. Luego de alojar Mary a un nuevo asilado de El Salvador, que dice llamarse José Luis Romero, con el pasar de los meses mientras él se ajusta a la vida clandestina en Albuquerque, ella aprende sobre la religión, el activismo y la violencia en su país. Esta termina por enamorarse de él aunque éste no le puede corresponder amorosamente por el trauma que sufrió en su país natal: después de haber asesinado al cura de su pueblo y a la hermana del cura, vinieron los soldados en busca de José Luis, seminarista y protegido del sacerdote asesinado. Se escapó del país antes de que lo mataran también. Luego de deshacerse la relación entre él y Mary en Albuquerque, ella da a luz a un hijo. Veinte años más tarde, Mary viaja con el joven a El Salvador en busca del padre. Aunque los tres no logran reunirse finalmente, José Luis le escribe a Mary una carta con la que cierra la narrativa con las noticias de que él está vivo y trabaja con el nuevo arzobispo salvadoreño para ayudar a los refugiados a volver a su país. En cuanto a Mary, la trayectoria de los hechos de la novela le ha permitido recobrar su lengua materna perdida, la identidad lingüística y cultural de sus antepasados, ahora rearticulada como una identidad latina trasnacional y hemisférica, dejando atrás el nacionalismo chicano de las décadas anteriores.

Mother Tongue se presenta como testimonio y narrativa confesional que Mary dirige a su hijo nacido durante la diáspora salvadoreña. El hecho de escribir la novela cumple con una promesa que ella hizo cuando el niño estuvo cerca de la muerte, llevando a cabo, así, una resignificación política de una práctica religiosa popular que aquí se cristaliza en un “collage-testimonio" innovador. ${ }^{7}$ Funcionando a la manera de un álbum o libro poético de recuerdos, que preserva la historia por medio de una reconstrucción personal y política de la diáspora, la novela integra elementos como artículos del periódico, boletines políticos, cartas, anotaciones en un diario personal, una lista de compras para ir al mercado, recetas y poemas de autores como Roque Dalton, Claribel Alegría y Pablo Neruda. Para Mary, narrar la historia de su relación con José Luis se liga necesariamente a lo que ella aprendió y vivió en esos años sobre la práctica de la teología de la liberación.

Al proveer refugio a José Luis y enamorarse de él, Mary aprende varios hechos importantes de la historia salvadoreña que subyacen en su historia personal. Como seminarista en El Salvador, José Luis tuvo que salir del país debido a la persecución de los escuadrones de la muerte que asesinaron al cura de su pueblo mientras rezaba la Misa y luego fueron en su propia busca. La religión y la política están no sólo ligadas en El Salvador como en Albuquerque, sino entrelazadas en los testimonios presentados a los activistas religiosos en los Estados Unidos; por ejemplo, cuando José Luis describe las condiciones en su país: "People are hiding their Bibles. If you are caught with one, the authorities assume not only that you are literate but that you might press for change. The government wants us to go back to the days when the Kingdom of God referred to heaven

${ }^{7}$ Para una versión anterior de este género, artística- e históricamente innovador, véase Zimmerman. 
only and not to what is possible on earth [La gente está escondiendo sus Biblias. Si te agarran con una, las autoridades presumen no sólo que sabes leer, sino que también podrías suscitar el cambio. El gobierno quiere regresar a la época en que el Reino de Dios se refería al cielo únicamente, y no a lo que era posible en la tierra]” (22). Tras la reterritorialización de la espiritualidad elaborada en la liberación teológica en El Salvador, y la relectura de La Biblia desde la perspectiva de los oprimidos, ya no se puede separar la religión de lo político. La religión ahora apoya e inspira los reclamos populares por la justicia. El gobierno, al contrario, insiste en que el reino de Dios se refiera solo al paraíso y no a la búsqueda de la justicia en la tierra.

Antes de presentar su testimonio en una reunión organizada por los Quakers en Albuquerque, José Luis se cubre la cara con un pañuelo azul que le ha prestado un refugiado guatemalteco para esconder su identidad. Simbólicamente juntando elementos de la vida de los teólogos de la liberación -la del Arzobispo Romero y la del Gustavo Gutiérrez, ${ }^{8}$ el discurso de José Luis cuenta la historia del liderazgo del Padre Gustavo, cura de su pueblo. Llevando a la práctica una democratización socialista contra el poder de la iglesia institucional, por medio de una comunidad cristiana de base en su pueblo, el Padre Gustavo organizó un grupo que estudiaba la Biblia los miércoles por la noche, con el propósito de reinterpretar las Beatitudes y enfocarse en la falta de agua y comida en el pueblo. José Luis cuenta cómo el padre usaba pupusas para el pan de la Comunión en la Misa, ceremonia que, según José Luis, estaba en el centro de la vida del pueblo. Un día, mientras alzaba el pan durante la Misa, asesinaron al cura. Dos días después, encontraron a la hermana de José Luis muerta y desmembrada detrás de la iglesia. Como seminarista patrocinado por el Padre Gustavo, José Luis tuvo que huir en los días siguientes ya que los escuadrones de la muerte lo estaban buscando a él también. Da testimonio de estos eventos en la reunión organizada por los Quakers en Albuquerque. La recuperación de su discurso en el libro de Martínez invoca la tradición del testimonio latinoamericano; el testimonio de José Luis se junta con la voz narrativa de Demetria Martínez para crear un doble discurso sobre la guerra civil salvadoreña y el exilio de los refugiados en los Estados Unidos.

En la esfera privada, distinta al discurso público del testimonio de José Luis, el altar que Mary ha construido en su dormitorio en 1982 representa un espacio alternativo con imágenes extraoficiales de la religión, que juntan lo sagrado y lo profano y le permiten a ella articular una distinta teoría feminista de la liberación teológica. En esta reinterpretación, Dios no se limita a ser hombre y blanco, y su cuerpo abusado sexualmente en la niñez se recupera por medio de un nuevo discurso religioso; este discurso surge de sus prácticas activistas y de su producción literaria llevada a cabo al escribir esta novela. Entre los objetos que se ven en el altar están las figuras del Santo Niño de Atocha y de la Virgen de Guadalupe, la tierra curativa del Santuario de Chimayó, agua bendita guardada en una botella de enjuague, y un incensario del Pueblo de Taos. Para Mary, estas imágenes religiosas eclécticas la hacen sentirse más cómoda con el Dios católico tradicional:

\footnotetext{
${ }^{8}$ Para ejemplos de la teología radical de estos dos sacerdotes véase Gutiérrez (We Drink From Our Own Wells, 1986) y Romero.
} 
I liked it that José Luis and I made love in the presence of my santos. I knew they had blessed my love for him, however imperfect it was, however mad. They were not like the white God I'd had to kill, that women like me must kill if we are to have any hope of ever finding God [Me gustaba que José Luis y yo hiciéramos el amor frente a mis santos. Yo sabía que ellos habían bendecido mi amor por él, a pesar de lo imperfecto, a pesar de la locura de ese amor. Mis santos no eran como el Dios blanco que tuve que aniquilar, el que las mujeres como yo tenemos que destruir para poder tener alguna esperanza de poder encontrar a Dios]. (59)

El espacio de contratexto que constituye este altar ayuda a Mary en su transformación de la imagen dominante de un dios masculino y blanco. Semejante a la forma experimental de la novela misma, cuyos recursos narrativos son elementos cotidianos eclécticos como el diario personal, los artículos del periódico y las listas de compras; Mary emplea el altar para lograr una relectura feminista de la teología oficial. Como ha señalado Turner, el altar de la casa reinventa el altar central de la liturgia oficial, permitiendo que la mujer misma funcione como una especie de sacerdote. En este espacio privado de su dormitorio, Mary practica, en cierto sentido, la narrativa pública que presenta José Luis sobre la liberación teológica del Padre Gustavo. Más allá del uso de pupusas en la misa por el cura, por ejemplo, los objetos sagrados de varias tradiciones espirituales en el altar de Mary, su comentario sobre sus experiencias sexuales con José Luis enfrente del altar, y la memoria del cuerpo abusado de su niñez convergen en este sitio para reinventar y reconstituir su concepción de Dios en términos feministas. La desacralización y desmitificación se hacen fuerzas de autodominio del cuerpo femenino, borrando así la misoginia católica que se inicia con el pecado de Eva. Ahora el cuerpo no es fuente del mal.

Igual que muchos católicos salvadoreños que adaptaron la religión a las nuevas metas de la justicia social, Mary y los otros personajes que trabajan en el Movimiento Santuario se desvían y redefinen el catolicismo tradicional y patriarcal. Cuando el hijo prematuro de Mary se encuentra entre la vida y la muerte, su madrina Soledad la aconseja ofrecer su sufrimiento a Dios. Esta resignación a un Dios patriarcal y paternalista que promueve el catolicismo ortodoxo se rearticula aquí para Mary en una nueva solidaridad política. Las palabras de Soledad "Offer up your pain for the mothers whose children are disappeared [Ofrece tu dolor por las madres cuyos hijos han desaparecido]” le permiten a Mary pasar por la crisis de su hijo enfermo y a la vez moldear la narrativa que está reconstruyendo para los lectores: "What I cannot remember, I will invent, offer up my tales for those who were not granted time enough to recall, to mend [Lo que no recuerdo, lo invento, ofrezco mis cuentos por aquellos que no han tenido tiempo suficiente para recordar, para reparar]" (91). De este modo, Martínez reterritorializa la religión y su narrativa dentro de una política hemisférica, evocando hasta a las madres de los desaparecidos en países latinoamericanos como Argentina, Chile, El Salvador y Guatemala, y a las víctimas de los conflictos violentos de toda la región.

Aunque el altar de Mary es ecléctico antes de que ella conozca a José Luis, al final de la novela transforma aún más con los símbolos de la nueva sabiduría personal y política de su creadora. El altar da cuerpo a las reelaboraciones feministas de su nuevo conocimiento de la teología de la liberación. Ahora Mary añade un ícono que invoca a las madres de los desaparecidos y otra imagen que representa su propio abuso sexual cuando era niña. 
Después de viajar a El Salvador veinte años después de su relación con José Luis, trae consigo una fotocopia de una foto de él con su nombre completo que encontró en un archivo de datos sobre los desaparecidos en la guerra civil. Mary modifica su altar, al añadir un ícono que claramente refiere a las manifestaciones de las madres de los desaparecidos y se atreve ir más allá con la inclusión de una imagen que representa el abuso sexual en su infancia. En la pared, Mary también coloca un cartel que le había regalado un obispo en El Salvador; este capta imágenes de Cristo y la Virgen María reconfigurados como una madre salvadoreña y su hijo desaparecido. En cuanto al cartel, Martínez ha notado que el intertexto visual que inspiró esta alusión en su novela es el cuadro del artista iconográfico Robert Lenz, “The Mother of the Disappeared [La Madre del Desaparecido]”, el cual retrata a la Virgen con la bufanda blanca como las que usan las Madres de la Plaza de Mayo en Argentina. En la mano, la Virgen tiene una corona de espinas, sufrimiento que promete proteger a sus hijos desaparecidos por toda Latinoamérica. ${ }^{9}$ De este modo, Martínez resitúa la historia de Mary y José Luis en un plano global como parte de la historia más amplia de la violencia en Latinoamérica en las décadas de los setenta y ochenta. Al pie del cartel, Mary sobrepone la reproducción de la foto de José Luis y la suya propia a los siete años cuando el vecino abusó sexualmente de ella. Al prender una vela ante estas tres imágenes, Mary da clausura a su condición de víctima, resultado que también se desdobla en la escritura de la novela misma que leemos. Cumpliendo con la promesa que le hizo a Dios veinte años antes por haber salvado a su hijo prematuro, con gran dificultad Mary le revela a su hijo por medio de la narrativa testimonial el dolor personal y político que subyace en la "historia" de su existencia.

A lo largo de toda la novela, Martínez emplea numerosas estrategias para implantar la nueva práctica de la teología de la liberación. Si la Biblia es el libro más importante de la religión ortodoxa, texto de control de otros y controlado a sí mismo por las interpretaciones sancionadas por la jerarquía masculina de la institución, los creyentes de la nueva teología tienen la capacidad de reinterpretar ellos mismos la escritura canónica y oficial del catolicismo. De tal manera, la protagonista cambia y reinventa su propia violación a los siete años para dar comienzo al proceso narrativo que culminará en la escritura de la novela: poco tiempo después de su violación, ella empieza a escribir con los lápices y en los cuadernos que su victimario llevó a su casa, encontrando esta vez las palabras que le faltaron en el momento de la violación. Rehusando que el violador controle su acto escritural, ella así trasciende el sentido negativo de la violación infantil. La novela también resignifica y recoloca a varios Otros, especialmente a los refugiados políticos de Centroamérica que han entrado ilegalmente a los Estados Unidos y a los que trabajan para ayudarlos en el Movimiento Santuario. Presenta a estos dos grupos en términos positivos con el fin de mostrar la manera en que se reapropian de lo cotidiano, empleando la política de la resignificación que les otorga la teología de la liberación. También utiliza elementos autobiográficos, construyendo macro y microestrategias de resignificación en el texto. Martínez utiliza elementos de su propio trabajo con los refugiados para demostrar la resignificación del Otro y las estrategias de resignificación.

${ }^{9}$ Conferencia de Demetria Martínez presentada en la Universidad de California, Santa Bárbara ya citada. Para la imagen de Lenz, véase www.natural-bridges.com. 
Cuando en diciembre de 1987 un gran jurado federal acusó a Martínez y al pastor luterano Glen Remer-Thamert de haber conspirado para ayudar a dos salvadoreñas a entrar en los Estados Unidos ilegalmente, ella insistió en que sólo estuvo allí para escribir un reportaje para el periódico Albuquerque Journal. Según la escritora, el ensayo periodístico constituía la rearticulación de una historia bíblica de la Navidad: dos mujeres embarazadas viajaban buscando asilo para dar a luz en el mes de diciembre. A la narrativa acusatoria del jurado federal, Martínez contrapone la historia de una narrativa que escribía como trabajo profesional, intercalando a la vez la versión rearticulada del episodio bíblico. La escritora elaboró varios segmentos de estas narrativas en su poesía de los años ochenta y más tarde en la novela Mother Tongue. ${ }^{10}$ En su poema "Nativity: For Two Salvadoran Women, 1986-1987 [El Nacimiento: Para dos mujeres salvadoreñas, 1986-87]" escrito en 1987, Martínez se dirige a las dos exiliadas que trataban de cruzar la frontera:

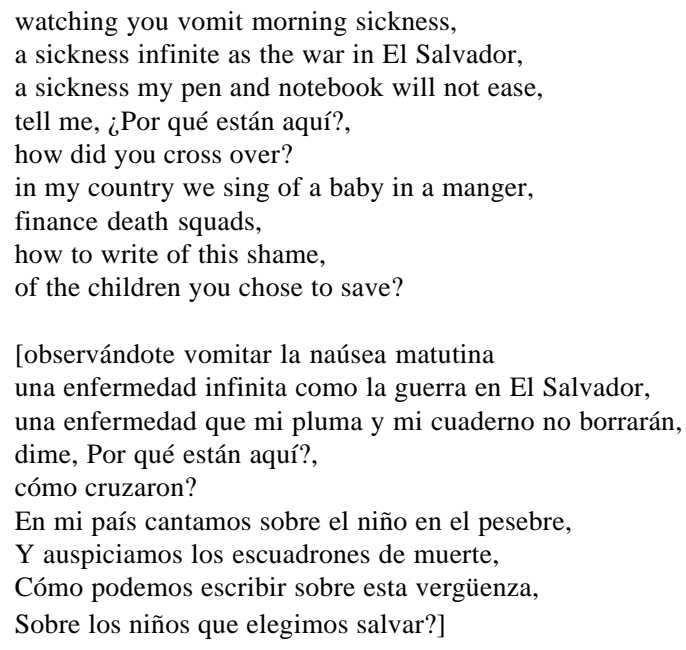

Al final Martínez sobrepone al lugar del nacimiento de Cristo el pueblo nuevomexicano del mismo nombre: "babies turn in your wombs,/ summoned to Belén to be born” (163). Aunque el gobierno empleó este poema contra ella en el proceso legal, el jurado la declaró inocente en 1989, bajo la protección de la primera enmienda de la constitución norteamericana.

\footnotetext{
${ }^{10}$ Véase Juan Bruce-Novoa, "New Mexican Chicano Poetry: The Contemporary Tradition,” in Erlinda Gonzales-Berry, ed. Pasó por aquí: Critical Essays on the New Mexican Literary Tradition, 1542-1988. Los poemas de Martínez "Postscript," "War” y "Point Blank” referidos a la guerra civil en El Salvador se encuentran en María Herrera-Sobek y Helena María Viramontes, eds., Chicana (W)rites on Word and Film; sobre el mismo tema en 1989 se publicaron otros poemas en Turning, en la colección Three Times a Woman. Para los detalles de la acusación contra Martínez, véase Jane Juffer, “An Ominous Indictment”.
} 
Tal resignificación discursiva de alterar y readaptar la macronarrativa de la historia de los Estados Unidos y El Salvador en los años ochenta, se da sobre la base de estrategias micronarrativas en el nivel discursivo de la ideología y la posibilidad de desvíos ideológicos que producen los enfrentamientos políticos (Hall). Varios grupos sociales, tanto los que tienen poder como los que no lo tienen, luchan siempre por asegurar o por cambiar el significado de signos lingüísticos dados en nuevas contextualidades y prácticas sociopolíticas. Por ejemplo, los afroamericanos en los Estados Unidos en los años sesenta reemplazaron el significado negativo de la palabra "negro” por los significados positivos “bello” y “poderoso”, logrando así implantar una política de la resignificación discursiva como parte de su lucha por los derechos civiles. Hardt y Negri también han señalado la importancia del nivel discursivo en el trabajo político de la multitud:

The first aspect of the telos of the multitude has to do with the senses of language and communication. If communication has increasingly become the fabric of production, and if linguistic cooperation has increasingly become the structure of productive corporeality, then the control over linguistic sense and meaning and the networks of communication becomes an ever more central issue for political struggle. (404)

Ya hemos señalado cómo Martínez reconstruye la macrohistoria que une a los Estados Unidos con El Salvador por medio de representaciones de trocitos de la vida, como secciones de un diario personal, poesía, recetas y boletines políticos; estos elementos micronarrativos se intercalan entre secciones de una narrativa autoreferencial que señala que el texto está escrito como una narrativa confesional dirigida al hijo de Mary. Así, resignifica elementos discursivos cotidianos y los desperdicios de la vida en un nuevo contexto, como anteriormente los afroamericanos resignificaron la palabra de desprecio “negro”. Reconfigurando lingüística y estéticamente elementos discursivos cotidianos, Martínez resignifica elementos de la microhistoria para contribuir al telos de la multitud latina transnacional que migra del sur al norte.

Cabe señalar que Martínez lleva el proceso de resignificación aún mas lejos: lo aplica a los elementos micronarrativos. Recupera la imagen de la sagrada familia con los nombres de los protagonistas Mary y José, y los conecta al país centroamericano que apela a Cristo -El Salvador. Igual a quienes practican la teología de la liberación rearticulando las narrativas bíblicas para interpretar los problemas contemporáneos de los pobres, Martínez explica en términos religiosos las estrategias de los miembros del Movimiento Santuario para ayudar a los refugiados. El grupo interpreta varias de las costumbres de los agentes inmigratorios en la frontera (como el no revisar a los hombres rubios angloamericanos) como una especie de liturgia de la que los miembros del Movimiento Santuario pueden estar seguros; así, el grupo emplea estos símbolos como si practicara una liturgia religiosa. Los miembros del grupo utilizan símbolos cotidianos, pero les añaden nuevos significados para facilitar su transporte clandestino de refugiados: i.e., emplean etiquetas engomadas con los nombres de Reagan y Bush en sus carros, tratan de simular viajes del diario vivir como ir de pesca y usan automóviles comunes como una vagoneta con una canoa encima. Los signos que el grupo emplea ligan así lo común con lo extraordinario, resignificando, tal como lo hicieron los practicantes de la teología de la liberación, al mezclar y superponer lo cotidiano con elementos sagrados tradicionales. 
En otra microestrategia de la resignificación, la protagonista Mary demuestra una nueva manera de ver al Otro latino en una ciudad como Albuquerque: “All over the city refugees were rendered invisible with each stroke of the sponge or rake they used to clean motel rooms and yards and porches [A través de la ciudad, los refugiados se tornaban invisibles con cada esponjazo o cada movimiento del rastrillo que usaban para limpiar los cuartos de motel y los jardines y patios]" (35). Como contraestrategia, Mary se enfoca en un signo visual que ve en la plaza, un "white patch of fabric [un pedazo blanco de tela]" que es la camiseta de José Luis y que lo distingue de los turistas que llevan ropa de Banana Republic. Ella relee los signos de la ropa que llevan los inmigrantes, para borrar su invisibilidad; nos hace verlos de nuevo. De este modo ella resignifica un signo sartorial dentro de la estructura social para relocalizar al Otro en la comunidad de los inmigrantes en Albuquerque.

La resignificación semántica a veces es difícil para los personajes e irrumpe violentamente en la novela. El doble significado de signos como el apelativo “Ana”, los trazos de figuras humanas en la calle y la campana de la iglesia, cortan e interrumpen la comunicación entre Mary y José Luis. Los significados funcionan en dos planos de códigos contradictorios: “Ana” se refiere tanto a una trabajadora en el Movimiento Santuario como a una amiga de José Luis asesinada en El Salvador; los trazos de figuras humanas significan para Mary un ejercicio de terapia sicológica mientras que para José Luis representan las amenazas y los asesinatos por los escuadrones de la muerte en El Salvador. José Luis consigna esta situación en su diario: “The problem is we’re not seeing or hearing the same things. Even church bells mean something different to us. [Mary] hears them and sets her watch. I hear them and remember the endless funerals in the villages outside the capital [El problema es que no estamos viendo ni escuchando lo mismo. Hasta las campanas de la iglesia significan algo diferente para cada uno. Mary las escucha y arregla su reloj. Yo las escucho y me recuerdan los infinitos funerales en los pueblos fuera de la capital]” (78). La novela resitúa estos signos en dos cadenas semióticas paralelas, semejante a la estrategia de la teología de la liberación que consiste en releer la Biblia en un nuevo contexto semiótico.

En In Search of Bernabé, Graciela Limón también relee la Biblia y varios motivos religiosos desde una perspectiva global, feminista y crítica de la injusticia social. Demuestra que la política y la religión están íntimamente ligadas y que todos deben continuamente reevaluar el sistema de valores morales en que creen. La nueva ética que propone la novela se desarrolla en un espacio trasnacional que cubre Centroamérica, México y los Estados Unidos. La protagonista es Luz Delcano quien es descendiente ilegítima de una familia poderosa salvadoreña, y quien tiene una abuela india y una madre africana. Al igual que Mary, Luz es víctima del abuso sexual: a los 13 años fue violada por su abuelo paterno. Aún a los 52 años se siente culpable ella misma del abuso de su abuelo que vuelve a repetirse por su patrón. Como mujer multirracial que pasa de ser víctima a hacerse mujer fuerte y moral, Luz simboliza también en la novela el país de El Salvador, donde los hijos nacidos de la violencia patriarcal se pelearon el uno contra el otro en la trágica guerra civil de los años ochenta. Representante de las figurativas cincuenta familias que han dominado la economía salvadoreña por décadas, el abuelo don Lucio Delcano viola a una de las más vulnerables personas del país. Aunque es impotente, recupera su 
poder sexual por medio de una fantasía sexual que posibilita la belleza exótica y juvenil de su nieta. Limón relee la Biblia para interpretar el acto del abuso: el epígrafe que abre el prólogo de la novela cita el capítulo 13 del libro de Daniel: "You have grown old in wickedness ... the sins of your earlier days have overtaken you ... This is how you have been behaving with the daughters of Israel and they were too frightened to resist ...” [Has envejecido en tu malicia...los pecados anteriores te han abatido...Así es que te has comportado con las hijas de Israel y ellas tenían demasiado miedo para resistir...] (9).

Luz dio a luz dos hijos que escogieron dos carreras contrarias: uno seminarista, y luego guerrillero, y el otro es coronel en el ejército; uno se mueve en los espacios religiosos y luego revolucionarios, y el otro es parte del poder. El seminarista, Bernabé, huye durante el ataque militar a la procesión del funeral del Arzobispo Romero en 1980, y participa en la lucha con la FMLN. Luz en busca de su hijo viaja por Guatemala, México y Los Angeles. En esta travesía se convierte en una mujer valiente y fuerte que al final tiene que confrontar la lucha entre sus dos hijos, quienes representan la división del país, y cuyas figuras reproducen la confrontación bíblica entre Caín y Abel. Luz, la mujer caída Eva, se convierte en la conciencia moral de la novela y corporalmente repite al final una imagen contemporánea de la Virgen María con su hijo muerto, La Pietá.

La novela comienza y termina con acontecimientos claves en la historia salvadoreña: el ataque al funeral del Arzobispo Oscar Romero enfrente de la catedral de San Salvador en 1980, y el acuerdo de paz que terminó con el conflicto civil en 1992. Otro hecho histórico central de la novela son los asesinatos, la noche del 16 de noviembre de 1989, de seis curas jesuitas y de una empleada y su hija en la Universidad Centroamericana. Cuando Limón viajó a El Salvador en 1990 como parte de una delegación internacional para conmemorar el aniversario de los asesinatos, ella y los otros delegados visitaron un pueblo en Chalatenango para asistir a las ceremonias conmemorativas y renombrar el lugar en honor de Ignacio Ellacuría, uno de los jesuitas asesinados. Aunque todos tenían documentos y permisos de tránsito, los militares los pararon muchas veces en el camino. En las noches en que durmieron en el patio de la iglesia del pueblo sólo se oían las descargas de ametralladoras. Al volver a Los Angeles, Limón añadió un prólogo nuevo a la novela en donde narró la violación de Luz Delcano por su abuelo. La violación incestuosa, Limón sugiere, es la metáfora apropiada para describir la guerra civil de más de diez años en El Salvador. ${ }^{11}$

Como parte del proyecto ideológico de la teología de la liberación y su ética de conciencia global, In Search of Bernabé reconfigura de un modo crítico la guerra civil salvadoreña como un conflicto internacional en el cual hay que reevaluar las categorías tradicionales del bien y el mal. Varios personajes toman decisiones éticas que son cuestionables -no solo un coronel del ejército y un hacendado, sino también un sacerdote norteamericano, un seminarista salvadoreño, una mujer desposeída que trabaja como criada y un guerrillero izquierdista. No se puede clasificar a la izquierda ni a la derecha como salvadores o diabólicos. Petra, por ejemplo, una “coyota” que por grandes cuotas transporta refugiados y obreros sin documentos a los Estados Unidos, no es maléfica de por sí. Incluso arriesga su vida cuando lleva a algunos indocumentados, que no tienen

11 Entrevista a Limón por la autora de este trabajo; marzo del 1998. 
donde quedarse, a un santuario católico en el centro de Los Angeles. ${ }^{12}$ Limón les sugiere a sus lectores norteamericanos que sus luchas están ligadas a las de otros países como El Salvador, y que son cómplices de la guerra y las muertes. La ética, la moral y la justicia social son coordenadas que articulan el discurso narrativo y la caracterización de los personajes situados en el contexto histórico de las guerras civiles de Centroamérica. Para substituir las categorías tradicionales del bien y el mal, Limón reconfigura tanto los personajes como los lectores como miembros de la comunidad global cuyas vidas están ligadas necesariamente, a pesar de sus localidades geográficas distintas en los Estados Unidos y El Salvador.

Tres personajes de la novela revelan de manera impresionante esa complejidad moral. Luz Delcano, por ejemplo, se caracteriza alternativamente como víctima del abuso sexual y como una defensora valiente de los derechos de otras víctimas; además, es una madre fuerte que busca sin cesar a su hijo desaparecido. Aunque algunos personajes en la novela la ven como "mujer caída”, ella también funciona como La Madre Santa a quien el hijo Bernabé constantemente invoca en los momentos difíciles. Cuando concluye la búsqueda -de ahí el título de la novela- Luz encuentra a su hijo muerto en un monte y lo abraza invocando así la imagen de La Pietá. Limón también conecta a Luz con la figura de Eva que llora "because her son murdered his brother [porque su hijo asesinó a su hermano]" (155). Pero en vez de culpar a la figura de Eva, en esta versión se resemantiza la narrativa bíblica del Génesis sobre las consecuencias del pecado original. Limón echa la culpa del fratricidio salvadoreño a un sacerdote norteamericano que simboliza a los ciudadanos estadounidenses. Semejante a Judas, este discípulo de Cristo ha traicionado a Bernabé y los hermanos salvadoreños, fomentando sin saberlo los largos años de la guerra de fratricidio en El Salvador.

Limón emplea la figura del Padre Hugh Joyce, profesor de una universidad católica estadounidense, para representar el estado moral comprometido en el cual se encuentran millones de ciudadanos norteamericanos cuyo gobierno ha gastado 400 millones de dólares para sostener la matanza en El Salvador (Howard 402). Durante las batallas intensas en San Salvador en noviembre de 1989, las peores de los diez años del conflicto, Luz narra un testimonio confesional sobre su vida al Padre Joyce mientras los dos se esconden para protegerse de la violencia bélica. Reconfigurando el acto sacramental de la confesión, Luz y el padre se confiesan mutuamente sus pecados, luego a la voz fantasma de un amigo del padre de su juventud, e implícitamente a los lectores del público que leen la novela. Al describir la destrucción física de las iglesias salvadoreñas durante la guerra, la narrativa de Luz implícitamente señala el papel del Padre Joyce en la matanza y la destrucción, y en el asesinato unos días después de los jesuitas en la UCA. Cuando el cura sale del refugio y sigue a las multitudes a la residencia jesuita, queda clara su conexión personal con la destrucción: cerca de los cuerpos se encuentran las cápsulas de las balas norteamericanas que el padre ha ayudado a vender a los militares salvadoreños. Como dice su amigo de la juventud: "We might as well have loaded the weapons ourselves ... We're

\footnotetext{
${ }^{12}$ Limón notó en dicha entrevista que su trabajo con los refugiados de El Salvador en Los Ángeles, en los ochenta, le reveló que, aunque en general son detestados en la cultura chicana, no todos los "coyotes” son malos. Después de sus entrevistas con refugiados salvadoreños, decidió presentar en su novela una perspectiva más amplia de los "coyotes”.
} 
a part of it all, and we did a good job ...” [Es como si nosotros mismos hubiéramos cargado las armas...Somos parte de todo eso, y lo logramos muy bien...] (149). Limón sugiere cómo el descarriado Padre Joyce compromete su universidad en la venta de armas que contribuye a la muerte y destrucción en El Salvador, así también cómo los líderes del gobierno estadounidense han involucrado a los ciudadanos norteamericanos con inversiones y ayuda fiscal que contribuyeron a la guerra civil salvadoreña. En los dos casos, los líderes responsables de la Iglesia Católica y de los Estados Unidos han llevado a sus constituyentes en un camino no-ético que ha ocasionado en la muerte de miles de salvadoreños.

La tercera figura de complejidad moral en la novela es el seminarista Bernabé que representa un Cristo falible. Invoca la imagen de Cristo tanto por ser seminarista como por llevar un crucifijo en la procesión a la catedral en San Salvador, durante el funeral del asesinado Arzobispo Romero, al comienzo de la novela. Después que los militares atacan al grupo con metralletas y granadas, Bernabé huye de la ciudad y comienza a luchar con la guerrilla. Al final de la novela, después de haber participado en varios asesinatos brutales bajo las tensiones de la guerra, cuestiona la ética de su trabajo guerrillero: “... when he ... realized that now he would never get to be a priest ... he had persuaded himself that instead of peace, the gospel preached by Jesus was really one of murder and torture ... he had falsely convinced himself that as a guerilla he could do more for his brothers and sisters than as a priest [...cuando él... se dio cuenta que ahora nunca iba a poder ser cura...se había convencido que en vez de la paz, el evangelio que predicó Jesús tenía que ver con el asesinato y la tortura...se había convencido falsamente que como guerrrillero podría lograr más para ayudar a sus hermanos y hermanas que como cura]” (134). Más tarde, Bernabé se da cuenta de que cuando mata a soldados y tortura a espías como guerrillero del FMLN, no hace caso del nexo humano entre él y sus víctimas: "the victims were his brothers, Salvadorans like him, and that each time he killed, he became less human [las víctimas eran sus hermanos, salvadoreños como él, y que cada vez que mataba, se tornaba menos humano]” (134). Limón implica que tal vez por esos pecados-los errores personales del juicio ético- la figura Bernabé-Cristo tiene que morir. La novela sugiere que todo el mundo debe vigilar tomas de decisiones extremas en que a veces se nos invita a participar, aun cuando luchamos por la justicia social. Al mostrar al sacerdote universitario y a la figura de Cristo como seres falibles, Limón exhorta a sus lectores, sin tanta conexión oficial con la moralidad y a la ética, a examinar su participación voluntaria e involuntaria en la matanza y destrucción en El Salvador.

La estructura de la novela se centra en dos asesinatos clericales, al principio y fin de la guerra civil: el del Arzobispo Romero en 1980 y el de los jesuitas en $1989 .{ }^{13}$ Como ejes centrales que entremezclan la religión y la política, estos hechos constituyen una marca dentro de la cual los sucesos y las imágenes de la novela se reinterpretan en esta adaptación novelística de la teoría y la práctica de la teología de la liberación. Limón relee la Biblia a la luz de la insurgencia política en Centroamérica y extiende esa óptica a una relectura del tumulto social por los valores éticos y morales. Rehusando caracterizar a la izquierda o a la derecha como enteramente buena o mala, construye una versión ecuánime de la

\footnotetext{
${ }^{13}$ Limón basa su descripción de la masacre de los jesuitas en los testimonios de testigos presenciales. Los detalles que presenta Torrens, por ejemplo, corresponden a los que emplea Limón.
} 
teología de la liberación semejante a la que desarrolló el teólogo Ignacio Ellacuría, uno de los jesuitas asesinados. En esta versión, no se acepta sin criticar ni las doctrinas izquierdistas ni las de derecha. Como ha señalado Phillip Berryman, Ellacuría fue el primer mártir de la teología de la liberación y sus ideas de la justicia social no siempre correspondían a las perspectivas del marxismo ortodoxo. Limón demuestra que la política y la religión están íntimamente conectadas, y que hay que revisar y criticar continuamente el sistema de valores morales. Ella no puede contar con exactitud la historia del conflicto salvadoreño si no reconfigura una serie de motivos bíblicos y de este modo crear una contranarrativa al gran texto de la religión oficial.

Como Martínez, Limón emplea varias resemantizaciones discursivas de la Biblia para construir su contranarrativa. Cuando al principio de la novela Bernabé lleva el crucifijo en la procesión, en efecto empieza su propia versión de la pasión y la muerte de Cristo que terminará en El Playón, el monte donde su madre encontrará su cuerpo. Su muerte se posterga por los sucesos violentos de la guerra civil en la que él asume funciones semejantes y opuestas a las de Cristo. Después del ataque a la procesión, Bernabé dirige a una multitud de salvadoreños al otro lado del Río Sumpul, ahora lleno de la sangre de otro ataque militar contra los que intentaban huir a Honduras. Luego desciende tres días al otro mundo y grita “Mamá, mamá, dónde estás?” (36), reconfigurando la invocación de Cristo a su padre durante la crucifixión. Cuando el Padre Joyce ve a Luz con el cuerpo muerto de su hijo, niega tres veces su propio papel en la matanza; las 40 monedas de plata de la narrativa bíblica se reconfiguran aquí como el prestigio personal del que goza el Padre Joyce como director de las inversiones lucrativas de su universidad. La historia de Caín y Abel se resignifica en la novela como el fratricidio literal y figurativo de la guerra civil salvadoreña. Así, Limón relee la Biblia en un nuevo contexto semiótico y social en el cual salvadoreños y norteamericanos reemplazan y reconfiguran los personajes bíblicos.

También como Martínez, Limón implementa su interpretación feminista de la teología al transformar al personaje de Luz, de ser víctima a una mujer fuerte que defiende los derechos de un exiliado maltratado y que sigue en la búsqueda incansable de su hijo desaparecido. Luz, como Mary en la novela de Martínez, reemplea los elementos del abuso del que fue víctima para hacerse fuerte. Si Mary comenzó a escribir con los lápices y cuadernos que le regaló el hombre que abusó de ella, encontrando así las palabras que le faltaron en el momento de la violación, para Luz la maternidad que ella reconfigura es el arma contra la violencia patriarcal de su vida y de la guerra. Aunque el título de la novela implica que el personaje central es Bernabé, la novela misma recoloca a Luz en el centro de la narración como una mujer con debilidades humanas y a la vez con una gran fuerza resistente. Por medio de la figura de Luz y el autoritarismo patriarcal hiperbolizado en varios personajes masculinos, Limón presenta una reconfiguración feminista sobre la teología de la liberación.

Si las interpretaciones alternativas de la Biblia por los teólogos de la liberación latinoamericanos representan un nuevo acercamiento al sufrimiento humano, las novelas de Martínez y Limón llevan el proceso a la siguiente etapa al recrearlo en la esfera literaria. Las narrativas bíblicas y sociales que emergen de la lucha por la dignidad humana en un país pequeño como El Salvador aparecen reconfiguradas en los textos de dos autoras chicanas. Martínez y Limón integran en su narrativa los conceptos de la teología 
revolucionaria que respaldaron las luchas por la justicia social en América Latina en las últimas décadas del siglo XX. Estas escritoras extienden la crítica de las estructuras económicas desiguales en Latinoamérica que promovió la teología de la liberación, a la desnaturalización de las estructuras patriarcales que oprimen a las mujeres y atrapan a los hombres generación tras generación. Las dos presentan a sus lectores norteamericanos un nuevo entendimiento de la globalización contemporánea en la cual las fronteras se borran y la ciudadanía es hemisférica. Su construcción estética se basa en una política global en la cual la justicia y la ética se construyen con respecto a la nueva multitud migratoria que trasciende las fronteras nacionales. Por medio de estas novelas, los sucesos cataclísmicos de un país pequeño de Latinoamérica emergen de la inconciencia política del público estadounidense. Martínez y Limón demuestran, como también han señalado Hardt y Negri, que hoy lo local es necesariamente un producto de la globalización. Las injusticias que surgen en el continuum hemisférico entre norte-sur y sur-norte que ha establecido la globalización, exigen una nueva ética basada en las revisiones discursivas y feministas de la teología de la liberación elaboradas en estas novelas chicanas.

\section{BiBLIOGRAFÍA}

Aguinis, Marcos. La cruz invertida. Barcelona: Planeta, 1970.

Argueta, Manilo. Un día en la vida. San Salvador: UCA Editores, 1980.

Benítez, Sandra. The Weight of All Things. New York: Halperin, 2000.

Berryman, Phillip. “Ignacio Ellacuría: An Appreciation”. America (7 July 1990): 12-15.

Bruce-Nova, Juan. “New Mexican Chicano Poetry: The Contemporary Tradition”. Pasó por aquí: Critical Essays on the New Mexican Literary Tradition, 1542-1988. Erlinda Gonzales-Berry, ed. Albuquerque: University of New Mexico Press, 1989. 267-96.

Cockroft, James D. Neighbors in Turmoil: Latin America. New York: Harper \& Row, 1989.

Cortázar, Julio. “Apolcalípsis en Solentiname”. Nicaragua tan violentamente dulce. Managua: Editorial Nueva Nicaragua, 1983.

Greimas, A. J. “Reflections on Actantial Models”. Narratology: An Introduction. Susan Ortega y José Ángel García Landa, eds. New York: Longman Publishing, 1996. 7689.

Gutiérrez, Gustavo. Essential Writings. James B. Nickoloff, ed. Maryknoll, NY: Orbis Books, 1996.

The Power of the Poor in History. Robert R. Barr, trad. Maryknoll, NY: Orbis Books, 1983.

We Drink from Our Own Wells: The Spiritual Journey of a People. Michael J. Oconnell, trad. Maryknoll, NY: Orbis Books, 1984.

Hall, Stuart. "The Rediscovery of 'Ideology': The Return of the Repressed in Media Studies”. Culture, Society, and the Media. Michael Gurevitch, Tony Bennett, James Curran y Janet Woollacott, eds. London: Routledge, 1982. 56-90.

Hardt, Michael y Antonio Negri. Empire. Cambridge, MA: Harvard University Press, 2000 . 
Herrera-Sobek, María y Helena María Viramontes (eds.) Chicana (W)rites on Word and Film. Berkeley: Third Woman Press, 1995. 42-46.

Howard, Richard A. “One Year Later”. America (24 Nov. 1990): 401-2

Isasi-Díaz, Ada María y Yolanda Tarango. Hispanic Women's Prophetic Voice in the Church: Toward a Hispanic Women's Liberation Theology. San Francisco: Harper and Row, 1988.

Juffer, Jane. “An Ominous Indictment”. Columbia Journalism Review 27/1 (1988): 4.

Leñero, Vicente. Jesuscristo Gómez. México: Ediciones Océano, 1986.

Limón, Graciela. In Search of Bernabé. Houston, TX: Arte Público Press, 1993. The Memories of Ana Calderón. Houston, TX: Arte Público Press, 1994.

Martínez, Demetria. Mother Tongue. Tempe, AZ: Bilingual Press, 1994. "Nativity: For Two Salvadoran Women, 1986-1987”. Turning in Three Times a Woman, Chicana Poetry. Tempe, Ariz.: Bilingual Review Press, 1989. 162-63. "What a Moment, When the 'Voiceless' Speak”. National Catholic Reporter (5 July 1996): 16.

Novak, Jorge. “La Iglesia Católica ha pecado mucho por omisión”. Entrevista de María Esther Gillio, Página/12 (10 de julio de 2001) http://www.pagina12.com.ar/2001/ 01-07/01-07-10/pag13.htm.

Romero, Archbishop Oscar. A Shepherd's Diary. Irene B. Hodgson, trad. Cincinnati: St. Anthony Messenger Press, 1993.

Voice of the Voiceless: The Four Pastoral Letters and Other Statements. Michael J. Walsh, trad. Maryknoll, NY: Orbis Books, 1985.

Tamez, Elsa (ed.). Through Her Eyes: Women's Theology from Latin America.Maryknoll, NY: Orbis Books, 1989.

Torrens, James S. “U.C.A.-The Witnesses Talk”. America (24 Nov. 1990): 394-400.

Turner, Kay. Beautiful Necessity: The Art and Meaning of Women's Altars. New York: Thames \& Hudson, 1999.

“Mexican American Home Altars: Towards Their Interpretation”. Aztlán 13/1-2 (1982): 309-325.

“Mexican American Women’s Home Altars: The Art of Relationship”. Ph.D. diss. University of Texas at Austin, 1990.

Welch, Sharon D. Communities of Resistance and Solidarity: A Feminist Theology of Liberation. Maryknoll, NY: Orbis Books, 1985.

Witvliet, Theo. The Way of the Black Messiah: The Hermeneutical Challenge of Black Theology as a Theology of Liberation. John Bowden, trad. Oak Park, IL: Meyer, Stone, and Co., 1987.

Zimmerman, Marc. El Salvador at War: A Collage Epic. Minneapolis: MEP Publications, 1988. 